\title{
Improved ASTM G72 Test Method for Ensuring Adequate Fuel-to-Oxidizer Ratios
}

\author{
REFERENCE: Juarez, A. and Harper, S.A., “Improved ASTM G72 Test Method for Ensuring \\ Adequate Fuel-to-Oxidizer Ratios,” Fourteenth International Symposium on Flammability and \\ Sensitivity of Materials in Oxygen-Enriched Atmospheres, STP 1596, E. Davis and T.A. Steinberg, \\ Editors, STP-2015-0080, ASTM International, West Conshohocken, PA. 2016.
}

\begin{abstract}
The ASTM G72/G72M-15 Standard Test Method for Autogenous Ignition Temperature of Liquids and Solids in a High-Pressure Oxygen-Enriched Environment is currently used to evaluate materials for the ignition susceptibility driven by exposure to external heat in an enriched oxygen environment. Testing performed on highly volatile liquids such as cleaning solvents has proven problematic due to inconsistent test results (non-ignitions). Non-ignition results can be misinterpreted as favorable oxygen compatibility, although they are more likely associated with inadequate fuel-to-oxidizer ratios. Forced evaporation during purging and inadequate sample size were identified as two potential causes for inadequate available sample material during testing. In an effort to maintain adequate fuel-to-oxidizer ratios within the reaction vessel during test, several parameters were considered, including sample size, pretest sample chilling, pretest purging, and test pressure. Tests on a variety of solvents exhibiting a range of volatilities are presented in this paper. A proposed improvement to the standard test protocol as a result of this evaluation is also presented. Execution of the final proposed improved test protocol outlines an incremental step method of determining optimal conditions using increased sample sizes while considering test system safety limits. The proposed improved test method increases
\end{abstract}

\footnotetext{
1 Standard Test Lead Flammability Test Engineer, Jacobs Engineering, White Sands Test Facility, Las Cruces, NM 88012.

2 Standard Test Project Manager, National Aeronautics and Space Administration, White Sands Test Facility/RF111, Las Cruces, NM 88012.
} 
2 Flammability and Sensitivity of Materials in Oxygen-Enriched Atmospheres

confidence in results obtained by utilizing the ASTM G72 autogenous ignition temperature test method and can aid in the oxygen compatibility assessment of highly volatile liquids and other conditions that may lead to false non-ignition results.

KEYWORDS: Autogenous ignition temperature, AIT, gaseous oxygen, liquid solvents, non-ignition, volatility, fuel-to-oxidizer ratio 


\section{Background}

The ASTM G72/G72M-09 Standard Test Method for Autogenous Ignition Temperature of Liquids and Solids in a High-Pressure Oxygen-Enriched Environment [1] is currently used to evaluate materials for the ignition susceptibility driven by exposure to external heat in an enriched oxygen environment. It is a valuable tool in the ranking of materials with respect to ignition susceptibility [2], even when external heat is not present. Autogenous ignition temperature (AIT) data ranking using ASTM G72 can aid greatly in selection of optimal materials for use in oxygen systems where ignition and flammability concerns are great. Occasionally during testing, the test system is heated to maximum temperature without ignition. Applying heat up to test system limits without ignition may at first be seen as potentially favorable data, indicating a non-flammable material. However, under closer inspection this non-ignition more likely indicates a lack of sufficient fuel-to-oxidizer ratio rather than an oxygen-compatible material. These false non-ignition results are often observed when testing liquids, such as cleaning solvents, with boiling points near or below ambient temperatures. Incorrect designation of materials as non-flammable due to test method shortfalls can be dangerous as it can lead to improper selection of optimal materials. Identification of a more robust method for the testing of low boiling point materials is critical, as poor selection of materials can lead to potentially catastrophic fire events in oxygen systems. This paper focuses on the evaluation of these (solvent) types of materials in an attempt to characterize a method to consistently obtain valid AIT test results.

\section{Test Scope and Approach}


Two liquid solvents, AK-225G ${ }^{\circledR 3}$ and HFE 7100, were tested using standard AIT test protocol outlined in ASTM G72. All testing presented was performed at the NASA White Sands Test Facility (WSTF) unless otherwise noted. The test approach was separated into three facets:

1. Reproduction/confirmation of historical results/re-familiarization with handling procedures

2. Identification/evaluation of variables for potential method improvement

3. Retesting of material using proposed potential method improvements

Reproduction of historical data on previously evaluated cleaning solvents was meant to act as a control to verify the test method. These reproduction tests also ensured an abundant amount of low boiling point solvents while providing an opportunity to re-familiarize personnel with the handling issues. ASTM G72 AIT Standard test methods were utilized in obtaining these data, with the exception of performing tests at $345 \mathrm{kPa}$ (50 psia) and 13.8 MPa (2000 psia) to replicate test conditions in a previous 2001 cleaning solvent evaluation [3]. In the 2001 evaluation, some of the solvents had been potentially erroneously reported as non-ignitable with AITs $>430^{\circ} \mathrm{C}\left(>800^{\circ} \mathrm{F}\right)$. During reproduction testing, reactions resulting in exotherms were noted, though temperature increases were insufficient to register as AITs. These exotherms were observed to occur at approximately $71^{\circ} \mathrm{C}\left(160^{\circ} \mathrm{F}\right)$. Although temperature exotherms did not increase rapidly enough to register an AIT, these results indicated the potential ignitability of the material. Since an ample amount of heat was provided to the test system, a lack of either fuel or oxidizer was suspected as the reason for inconsistent test results.

To ensure adequate levels of fuel or oxidizer during testing, the following variables were investigated:

1. Sample size, to assess sufficient fuel availability

2. Pretest sample chilling, to assess sufficient fuel availability

3. Pretest reaction vessel purging, to assess sufficient fuel and oxidizer availability

4. Test pressure, to assess sufficient oxidizer availability

3 AK-225G ${ }^{\circledR}$ is a registered trademark of Asahi Glass Company LTD., Tokyo, Japan. 
Sample Size-The most obvious of the effective test parameters was the sample size. ASTM G72 limits the sample size to $230 \mathrm{mg}$. The existence of exotherms without ignition suggested a combustion reaction with insufficient conditions to register an AIT. Though this size is more than adequate for materials that are solid or viscous at room temperate, the evaporative loss of the low boiling point material could have resulted from an insufficient sample size. An incremental sample size increase approach (approximately 0.25 g step size) was implemented in which system safety limits were evaluated prior to testing at each step size until repeatable AIT data were obtained. Once repeatable results were obtained, the effect of even larger test samples was also evaluated.

Sample Chilling—Chilling samples just prior to test is a practice that has been used by other labs such as WHA International, Inc. (Las Cruces, NM) in an attempt to minimize the evaporation of low boiling point liquids. Chilling was considered good practice and was implemented in this test series to minimize losses of the measured amount of test material during its transfer to the reaction vessel and before initiation of testing. Chilling of the specimens was achieved by immersing the test tubes, containing known quantities of test material, into an ice bath (Fig. 1). Results evaluating the influence of this modification to the test procedure are presented in this paper.

Reaction Vessel Purging - A tradeoff was suspected concerning the efficacy of pretest purging. On the one hand, purging ensures the evacuation of trapped atmospheric gas; but alternatively, purging encourages the evaporation and venting of volatized test material. This parameter may affect pretest oxidizer and fuel levels. For this evaluation, all purging consisted of the following:

1. Measuring out desired amount of chilled material by weight

2. Securing the sample within the pressure vessel

3. Performing three 1-min purges at test pressure

4. Removing the sample and weighing the mass remaining within test tube 
Test Pressure-Testing was performed at $345 \mathrm{kPa}$ (50 psia) as a deviation from the standard G72 AIT protocol to assess ignitability conditions at low oxygen pressures. Occasionally during this low-pressure testing, AIT results were inconsistent or testing resulted in non-ignitions. At $345 \mathrm{kPa}$ (50 psia), available oxidizer may have been insufficient. As a result of this observation, an incremental increase in pressure was implemented to ensure adequate oxidizer levels.

Upon completion of the variable investigation, changes were implemented to the test method and further tests were performed to evaluate the combined effect of the individual test parameters.

\section{Test Results}

Reproduction of historical data represents tests involving two solvents previously evaluated (Table 1). The results from tests performed on HFE 7100 and AK-225G were used as baseline data for comparison to three other candidate volatile cleaning solvents (see following section: Modified Test Protocol and Test Results).

The results of each of the previously described variables are discussed in this section. Triplicates of each test were performed, unless otherwise noted.

Sample Size and Fuel Availability

The results of the sample size study are presented in Table 1 . Sample sizes were incrementally increased by $0.25 \mathrm{~g}$ at each pressure until AITs were observed. Temperature Limit (TL) indicates tests in which the TLs of the test system were reached with no clear ignition detected.

Once a sample size was obtained in which repeatable ignitions were obtained, no noticeable effect was observed when increasing the sample size further. An increase in pressure tended to lower the AIT due to more available oxidizer, as expected. 
Though baseline solvents had been believed to be non-ignitable in previous testing [3,4] tests with an increased sample size of $500 \mathrm{mg}$ for each of the two baseline solvents resulted in AITs when tested at 13.8 MPa (2000 psia). AITs were observed at low pressure when testing HFE 7100 at $345 \mathrm{kPa}$ (50 psia); however, no AITs were observed for AK-225G at that pressure. A lack of oxygen was suspected as a cause for the absence of any reactions when testing AK-225G at $345 \mathrm{kPa}$ (50 psia). Pressures were increased, and AK-225G was tested at $483 \mathrm{kPa}$ (70 psia), yielding an AIT higher than recorded at higher pressures. Higher reported AITs at lower pressure are typical as a result of lower amounts of available oxidizer.

Findings from the sample size investigation concluded $1000 \mathrm{mg}$ is an optimal level for solvent evaluation testing across the various materials tested, and will likely be sufficient in the majority of future low boiling point liquid testing. Averages and standard deviations are reported in Table 1 for all triplicates performed.

Pretest Purges and Oxidizer Availability

Results of the purge mass loss evaluation indicate more mass was lost to purging at higher pressure for each of the solvents than at lower pressure. Approximately the same amount of solvent was lost during purging regardless of the initial sample size. Table 2 presents the results of the purge mass loss evaluation for AK-225G and HFE-7100.

It was found that an inherent outcome of the purging process is the loss of some of the sample, and at higher test pressures this loss becomes a significant factor when compared to initial sample mass. The evaluation of pretest purging on final test results is presented in Table 1. Baseline solvent tests for AK-225G and HFE-7100 are also presented in Table 1 for direct comparison.

The influence of residual air within the reaction vessel was most notable at lower pressures due the ratio of air to oxygen. The data set for AK-225G at 70 psia in Table 1 is a good example of how the lack of 100 percent oxygen pretest purges influences test results. When starting with a sufficiently large 
sample size, some loss of sample due to purging was acceptable. But insufficient oxidizer, regardless of the sample size present, resulted in non-ignitions.

Test Pressure and Oxidizer Availability

The lack of AIT ignitions for AK-225G at lower pressures resulted in suspected insufficient oxidizer to support reactions, and a retest was performed at a slightly higher pressure (483 kPa (70 psi)). In this low-pressure range, the fuel-to-oxidizer ratio was found to be very sensitive. In addition to oxidizer availability via test pressure, pretest purging was found to be important in removing residual air and ensuring that a 100\% oxygen environment provided sufficient oxidizer at $483 \mathrm{kPa}$ (70 psi), as can be seen in Table 1. The lack of purging resulted in tests that reached the TL of the test system without ignition (Table 1). In addition, obtaining the ideal "sweet spot" for fuel-to-oxidizer ratios at these low pressures required the largest tested sample size below which no ignitions were observed. Pretest purging with oxygen to guarantee a 100\% oxygen environment yields ignitions during testing of $1000 \mathrm{mg}$ AK-225G at the increased test pressure of $483 \mathrm{kPa}$ (70 psia). As a result of these findings, three purges with incrementing test pressure until consistent ignitions are obtained was deemed the preferred method for the refined test protocol.

\section{Modified Test Protocol and Test Results}

Three more volatile solvents, Solvay Solvokane ${ }^{\circledR},{ }^{4} 3 \mathrm{M} \mathrm{L}-14780^{\circledR 5}$ developmental solvent, and Honeywell Solstice ${ }^{\circledR 6}$ performance fluid (PF) were tested using the modified AIT test protocol, outlined as follows:

1. Pre-chilling of test material

2. $1000 \mathrm{mg}$ test sample

\footnotetext{
4 Solvokane ${ }^{\circledR}$ is a registered trademark of Solvay Corporation, Buxelles, Belgium.

5 L-14780® is a registered trademark of 3M Company, St. Paul, MN.

6 Solstice ${ }^{\circledR}$ is a registered trademark of Honeywell International, Inc., Morristown, NJ.
} 
3. 3 pretest purges at test pressure

4. Incremental increase in pressure at low pressures until repeatable igntions are obtained

Results are displayed in Table 3. Average AITs and standard deviations (SDs) are displayed in the grey boxes for each of the triplicates performed. To ensure safe operation of the test system, sample sizes were incrementally increased to $1000 \mathrm{mg}$ when testing at the highest pressure, $13.8 \mathrm{MPa}$ (2000 psia). No appreciable differences were found between results obtained at 500 and $1000 \mathrm{mg}$ for any of the materials tested. Triplicates were performed with $1000 \mathrm{mg}$ of material at each pressure.

No ignitions were observed for AIT tests conducted with L-14780 at $345 \mathrm{kPa}$ (50 psia) or $483 \mathrm{kPa}$ (70 psia); therefore, per established modified protocol, pressures were further increased to 1.38 MPa (200 psia), at which point an AIT was observed. Only one test was conducted at these conditions due to funding constraints, though repeatability was anticipated in this pressure range. As before, lower pressures resulted in higher AITs, indicating more energy is required to ignite materials at lower pressures due to the decreased availability of oxidizer.

Three extra tests were performed with non-chilled Solvokane at the various pressures to further investigate the effects of pre-chilling the solvents prior to test. One test using $1000 \mathrm{mg}$ at each pressure was performed with no appreciable change in results, indicating that AITs are more dependent on initial sample size and that minimized evaporation due to pre-chilling of sample material was not a major contributing factor in ensuring fuel availability. These test results are presented in Table 3 under the Not-Chilled (NC) column.

Combustion by-products for each of the solvents resulted in acidic environments that degraded the components within the reactions vessel. Some etching of the reaction vessels was noted, however not enough to compromise the integrity of the vessel. Thermocouples were the most affected components; $1.59 \mathrm{~mm}$ (0.0625 in.) sheathed thermocouples were used during testing and were often corroded. This corrosion did not adversely affect test results, and the thermocouples were routinely replaced.

\section{Conclusions}


Successful application of the AIT test method on low boiling point materials was performed due to some modifications to the method. Legacy testing has shown to be incomplete, and a method of mitigating shortcomings of the test method has been developed.

Assurance of adequate fuel-to-oxidizer ratios was found to be critical in obtaining valid data. Purging and incremental pressure increases in low-pressure conditions were found to be effective in ensuring sufficient oxidizer. Larger sample size played a significant role in ensuring sufficient fuel and the acquisition of reliable data. These practices ensure that abundant amounts of both fuel and oxidizer, as required for combustion, are available within the reaction vessel at the time of testing. An incremental step method for obtaining an adequate sample size for testing without compromising system or personnel safety was developed and proven successful.

Pre-chilling the sample material was shown to be unnecessary for the solvents tested; however, pre-chilling was considered good practice as a means of due diligence in obtaining quality data.

The final method for obtaining reliable ASTM G72 AIT data when evaluating low boiling point materials, as well as other materials suspected of possessing inadequate fuel-to-oxidizer ratios, should follow the guidelines outlined in this paper, summarized as follows:

1. Use test samples of $1000 \mathrm{mg}$ or greater until repeatable ignitions are obtained (while ensuring system safety limits are not exceeded).

2. Pre-chilling of test material is good practice, but not required.

3. Perform three pretest purges at test pressure to ensure sufficient oxidizer availability.

4. Incrementally increase test pressure at low pressures until repeatable ignitions are obtained.

High pressures should suffice as an evaluation tool due to the more severe conditions. If lower pressures are required, a modification of the test method can ensure adequate oxygen is available for combustion by incrementally increasing the pressure until reactions are observed.

\section{Acknowledgements}


The authors would like to acknowledge the test team's hard work in the production of the test data: John Bouvet and Steve Bailey, as well as WHA International, Inc. for consulting on their past low boiling point material testing best practices.

\section{References}

[1] ASTM G72/G72M-09, Standard Test Method for Autogenous Ignition Temperature of Liquids and Solids in a High-Pressure Oxygen-Enriched Environment, ASTM International, West Conshohocken, PA, 2009, www.astm.org.

[2] Burns, H.D., Farner, B.R., Harper, S.A., Peralta, S.F., Lowrey, N.M., Ross, H.R., and Juarez, A., NASA/TP-2015-218207, Replacement of Hydrochlorofluorocarbon-225 Solvent for Cleaning and Verification Sampling of NASA Propulsion Oxygen Systems Hardware, Ground Support Equipment, and Association Test Systems, National Aeronautics and space Administration, Washington, DC, April 2015.

[3] Goldberg, J.S., Delgado, R.H., Biesinger, P., Hornung, S.D., and Beeson, H.D., United States Air Force Wipe Solvent Testing, WSTF-IR-0134-002-01, NASA Johnson Space Center White Sands Test Facility, Las Cruces, NM, September 2001.

[4] Beeson, H., Beisinger, P., "Evaluation of Solvent Alternatives for Cleaning of Oxygen Systems,” Proceedings of the Third Aerospace Environmental Technology Conference, Huntsville, AL, June 1998, NASA/CP-1999-209258. 


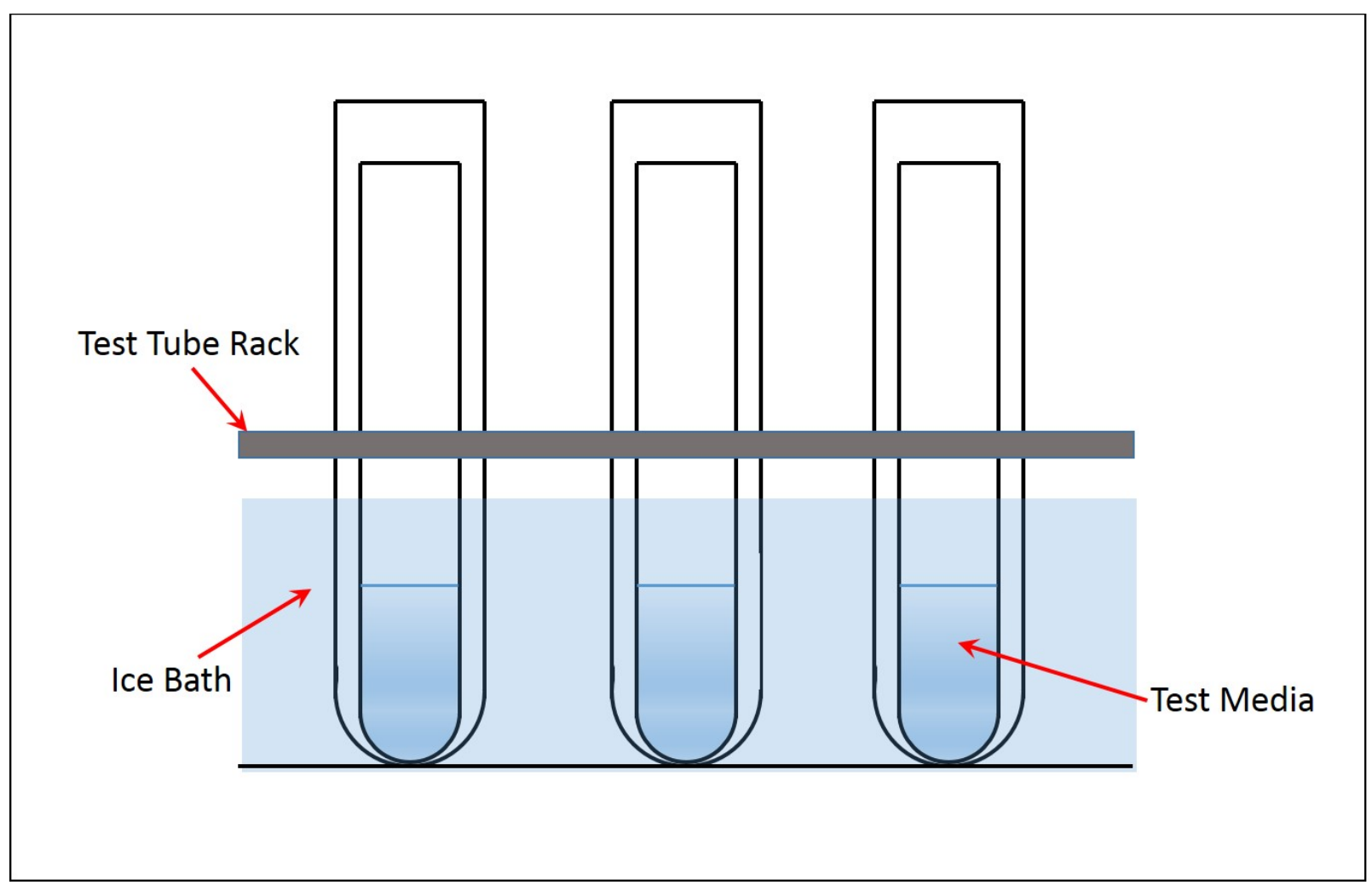

FIG. 1-Sample Chilling Apparatus. 
TABLE 1-AIT method parameter evaluation and method improvement test matrix (sample size, pretest oxidizer purges, pressure).

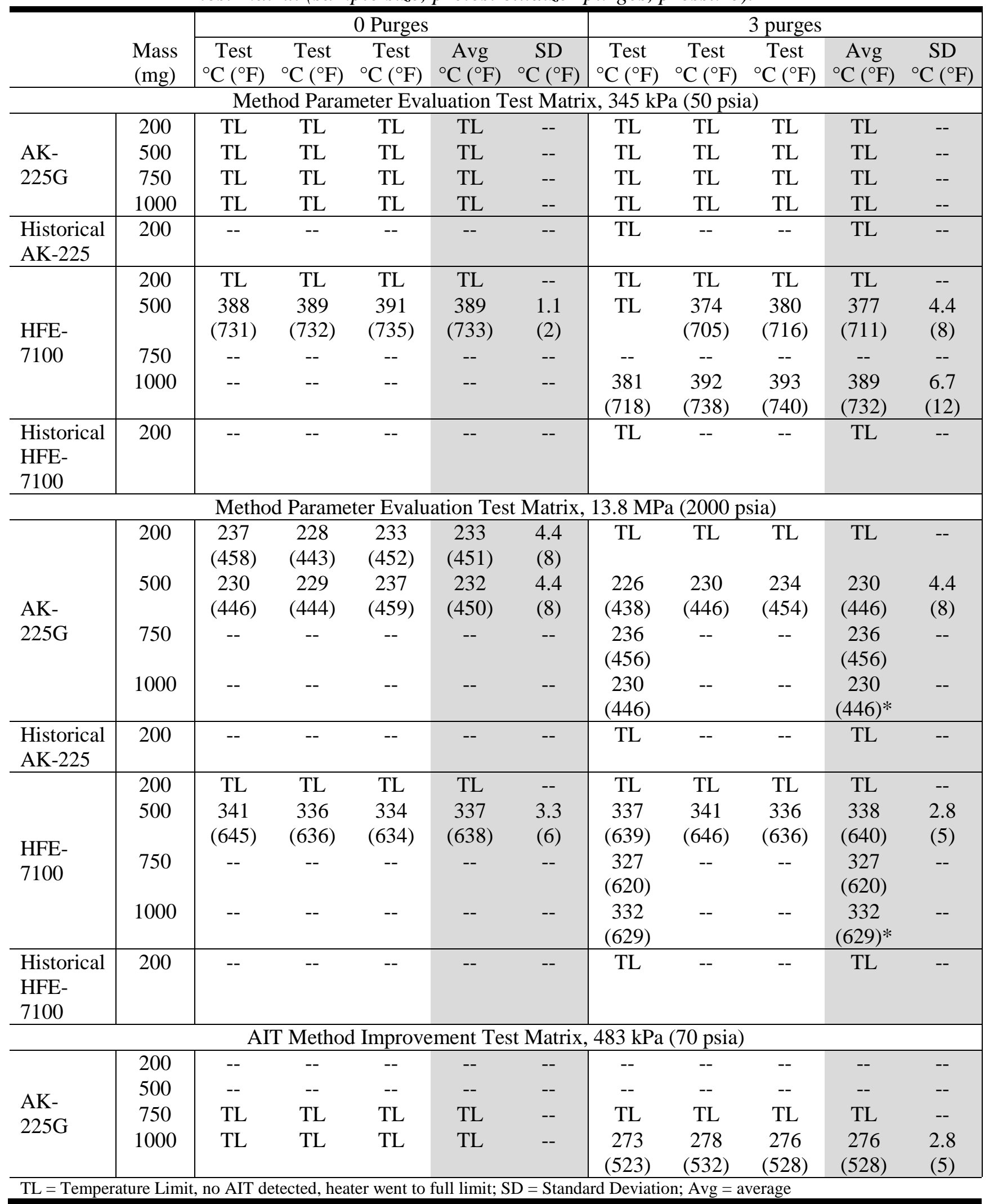


TABLE 2-AK-225G and HFE-7100 Purge Mass Loss Evaluation.*

\begin{tabular}{|c|c|c|c|c|c|c|c|c|}
\hline $\begin{array}{c}\text { Purge } \\
\text { Pressure } \\
\text { MPa (psia) }\end{array}$ & $\begin{array}{c}\text { Pretest } \\
\text { Temperature } \\
{ }^{\circ} \mathrm{C}\left({ }^{\circ} \mathrm{F}\right)\end{array}$ & $\begin{array}{l}\text { Pretest } \\
\text { Mass } \\
\text { (mg) }\end{array}$ & $\begin{array}{l}\text { Posttest } \\
\text { Mass } \\
\text { (mg) }\end{array}$ & $\begin{array}{l}\text { Mass } \\
\text { Loss } \\
(\mathrm{mg})\end{array}$ & $\begin{array}{l}\text { Mass } \\
\text { Loss } \\
(\%)\end{array}$ & $\begin{array}{l}\text { Avg. Mass } \\
\text { Loss } \\
\text { (mg) }\end{array}$ & $\begin{array}{l}\text { Avg. Mass } \\
\text { Loss } \\
(\%)\end{array}$ & $\begin{array}{c}\text { Standard } \\
\text { Deviation } \\
(\mathrm{mg})\end{array}$ \\
\hline \multicolumn{9}{|c|}{ AK-225G } \\
\hline \multirow{6}{*}{$\begin{array}{c}0.3 \\
(50)\end{array}$} & $2.2(36)$ & 169 & 149 & 20 & 11.8 & \multirow{3}{*}{18.3} & \multirow{3}{*}{10.8} & \multirow{3}{*}{2.1} \\
\hline & $2.2(36)$ & 167 & 151 & 16 & 9.6 & & & \\
\hline & $2.2(36)$ & 171 & 152 & 19 & 11.1 & & & \\
\hline & $2.2(36)$ & 515 & 497 & 18 & 3.5 & \multirow{3}{*}{15} & \multirow{3}{*}{2.9} & \multirow{3}{*}{8.9} \\
\hline & $1.7(35)$ & 506 & 484 & 22 & 4.3 & & & \\
\hline & $1.7(35)$ & 505 & 500 & 5 & 1.0 & & & \\
\hline \multirow{6}{*}{$\begin{array}{c}6.9 \\
(1000)\end{array}$} & $2.2(36)$ & 185 & 151 & 34 & 18.4 & \multirow{3}{*}{31.3} & \multirow{3}{*}{15.2} & \multirow{3}{*}{4.6} \\
\hline & $3.3(38)$ & 230 & 196 & 34 & 14.8 & & & \\
\hline & $-1.1(30)$ & 210 & 184 & 26 & 12.4 & & & \\
\hline & 3.9 (39) & 519 & 488 & 31 & 6.0 & \multirow{3}{*}{34} & \multirow{3}{*}{6.8} & \multirow{3}{*}{4.4} \\
\hline & $-1.1(37)$ & 496 & 457 & 39 & 7.9 & & & \\
\hline & $3.9(39)$ & 485 & 453 & 32 & 6.6 & & & \\
\hline \multirow{6}{*}{$\begin{array}{c}13.8 \\
(2000)\end{array}$} & $0.6(33)$ & 227 & 146 & 103 & 35.7 & \multirow{3}{*}{58.7} & \multirow{3}{*}{26.4} & \multirow{3}{*}{22.5} \\
\hline & $2.2(36)$ & 219 & 183 & 81 & 16.4 & & & \\
\hline & $3.3(38)$ & 217 & 158 & 36 & 27.2 & & & \\
\hline & $-1.1(30)$ & 482 & 446 & 59 & 7.5 & \multirow{3}{*}{40.7} & \multirow{3}{*}{8.3} & \multirow{3}{*}{4.0} \\
\hline & $-0.6(31)$ & 488 & 445 & 36 & 8.8 & & & \\
\hline & $0.6(33)$ & 502 & 459 & 43 & 8.6 & & & \\
\hline \multicolumn{9}{|c|}{ HFE-7100 } \\
\hline \multirow{6}{*}{$\begin{array}{c}0.3 \\
(50)\end{array}$} & $0.6(33)$ & 204 & 189 & 15 & 7.4 & \multirow{3}{*}{13.3} & & \\
\hline & $-1.1(30)$ & 214 & 198 & 16 & 7.5 & & 6.2 & 3.8 \\
\hline & $-1.1(30)$ & 235 & 226 & 9 & 3.8 & & & \\
\hline & $-1.1(30)$ & 489 & 477 & 12 & 2.5 & & & \\
\hline & $-1.1(30)$ & 516 & 505 & 11 & 2.1 & 13 & 2.6 & 2.6 \\
\hline & $-1.1(30)$ & 516 & 500 & 16 & 3.1 & & & \\
\hline & $-1.1(30)$ & 230 & 198 & 32 & 13.9 & & & \\
\hline & $-1.1(30)$ & 190 & 167 & 23 & 12.1 & 27 & 12.5 & 4.6 \\
\hline 6.9 & $-1.1(30)$ & 226 & 200 & 26 & 11.5 & & & \\
\hline (1000) & $-1.1(30)$ & 520 & 507 & 13 & 2.5 & & & \\
\hline & $-1.1(30)$ & 514 & 483 & 31 & 6.0 & 25 & 4.9 & 10.4 \\
\hline & $-1.7(29)$ & 514 & 483 & 31 & 6.0 & & & \\
\hline & $-0.6(31)$ & 219 & 203 & 16 & 7.3 & & & \\
\hline & $0.0(32)$ & 223 & 184 & 39 & 17.5 & 28.3 & 12.8 & 11.6 \\
\hline 13.8 & $0.6(33)$ & 223 & 193 & 30 & 13.5 & & & \\
\hline (2000) & $2.8(37)$ & 507 & 438 & 69 & 13.6 & & & \\
\hline & 1.7 (35) & 513 & 476 & 37 & 7.2 & 58.3 & 11.5 & 18.5 \\
\hline & $1.1(34)$ & 509 & 440 & 69 & 13.6 & & & \\
\hline
\end{tabular}


15 Flammability and Sensitivity of Materials in Oxygen-Enriched Atmospheres

TABLE 3-Final AIT Data using Modified Test Method.

\begin{tabular}{|c|c|c|c|c|c|c|c|c|c|c|c|c|c|c|c|c|c|c|c|c|c|c|c|c|c|}
\hline & \multirow[b]{3}{*}{$\begin{array}{l}\text { Mass } \\
(\mathrm{mg})\end{array}$} & \multicolumn{6}{|c|}{$\begin{array}{c}345 \mathrm{kPa} \\
\text { (50 psia) } \\
\end{array}$} & \multicolumn{6}{|c|}{$\begin{array}{c}483 \mathrm{kPa} \\
\text { (70 psia) }\end{array}$} & \multicolumn{6}{|c|}{$\begin{array}{l}1.38 \mathrm{MPa} \\
\text { (200 psia) }\end{array}$} & \multicolumn{6}{|c|}{$\begin{array}{c}13.8 \mathrm{MPa} \\
(2000 \text { psia) }\end{array}$} \\
\hline & & \multicolumn{5}{|c|}{ Chilled } & \multirow{2}{*}{$\begin{array}{c}\text { NC } \\
\text { Test } \\
{ }^{\circ} \mathrm{C}\left({ }^{\circ} \mathrm{F}\right)\end{array}$} & \multicolumn{5}{|c|}{ Chilled } & \multirow{2}{*}{$\begin{array}{c}\mathrm{NC} \\
\text { Test } \\
{ }^{\circ} \mathrm{C}\left({ }^{\circ} \mathrm{F}\right)\end{array}$} & \multicolumn{5}{|c|}{ Chilled } & \multirow{2}{*}{$\begin{array}{c}\text { NC } \\
\text { Test } \\
{ }^{\circ} \mathrm{C}\left({ }^{\circ} \mathrm{F}\right)\end{array}$} & \multicolumn{5}{|c|}{ Chilled } & \multirow{2}{*}{$\begin{array}{c}\text { NC } \\
\text { Test } \\
{ }^{\circ} \mathrm{C}\left({ }^{\circ} \mathrm{F}\right)\end{array}$} \\
\hline & & $\begin{array}{c}\text { Test } \\
{ }^{\circ} \mathrm{C}\left({ }^{\circ} \mathrm{F}\right) \\
\end{array}$ & $\begin{array}{c}\text { Test } \\
{ }^{\circ} \mathrm{C}\left({ }^{\circ} \mathrm{F}\right) \\
\end{array}$ & $\begin{array}{c}\text { Test } \\
{ }^{\circ} \mathrm{C}\left({ }^{\circ} \mathrm{F}\right) \\
\end{array}$ & $\begin{array}{c}\text { Avg } \\
{ }^{\circ} \mathrm{C}\left({ }^{\circ} \mathrm{F}\right) \\
\end{array}$ & $\begin{array}{c}\mathrm{SD} \\
{ }^{\circ} \mathrm{C}\left({ }^{\circ} \mathrm{F}\right. \\
\end{array}$ & & \begin{tabular}{|c|} 
Test \\
${ }^{\circ} \mathrm{C}\left({ }^{\circ} \mathrm{F}\right)$ \\
\end{tabular} & $\begin{array}{c}\text { Test } \\
{ }^{\circ} \mathrm{C}\left({ }^{\circ} \mathrm{F}\right) \\
\end{array}$ & $\begin{array}{c}\text { Test } \\
{ }^{\circ} \mathrm{C}\left({ }^{\circ} \mathrm{F}\right) \\
\end{array}$ & $\begin{array}{c}\text { Avg } \\
{ }^{\circ} \mathrm{F}\end{array}$ & $\begin{array}{l}\text { SD } \\
{ }^{\circ} \mathrm{F}\end{array}$ & & $\begin{array}{c}\text { Test } \\
{ }^{\circ} \mathrm{C}\left({ }^{\circ} \mathrm{F}\right) \\
\end{array}$ & $\begin{array}{c}\text { Test } \\
{ }^{\circ} \mathrm{C}\left({ }^{\circ} \mathrm{F}\right) \\
\end{array}$ & $\begin{array}{c}\text { Test } \\
{ }^{\circ} \mathrm{C}\left({ }^{\circ} \mathrm{F}\right) \\
\end{array}$ & $\begin{array}{c}\text { Avg } \\
{ }^{\circ} \mathrm{C}\left({ }^{\circ} \mathrm{F}\right) \\
\end{array}$ & $\begin{array}{c}\mathrm{SD} \\
{ }^{\circ} \mathrm{C}\left({ }^{\circ} \mathrm{F}\right) \\
\end{array}$ & & $\begin{array}{c}\text { Test } \\
{ }^{\circ} \mathrm{C}\left({ }^{\circ} \mathrm{F}\right) \\
\end{array}$ & $\begin{array}{c}\text { Test } \\
{ }^{\circ} \mathrm{C}\left({ }^{\circ} \mathrm{F}\right) \\
\end{array}$ & $\begin{array}{c}\text { Test } \\
{ }^{\circ} \mathrm{C}\left({ }^{\circ} \mathrm{F}\right) \\
\end{array}$ & $\begin{array}{c}\text { Avg } \\
{ }^{\circ} \mathrm{C}\left({ }^{\circ} \mathrm{F}\right) \\
\end{array}$ & $\begin{array}{c}\mathrm{SD} \\
{ }^{\circ} \mathrm{C}\left({ }^{\circ} \mathrm{F}\right) \\
\end{array}$ & \\
\hline \multirow{4}{*}{ Solvokane } & 200 & -- & -- & -- & -- & -- & -- & -- & -- & -- & -- & -- & -- & -- & -- & -- & -- & -- & -- & $\mathrm{TL}$ & -- & -- & -- & -- & -- \\
\hline & 500 & -- & -- & -- & -- & -- & -- & -- & -- & -- & -- & -- & -- & -- & -- & -- & -- & -- & -- & $\begin{array}{c}147 \\
(296)\end{array}$ & -- & -- & -- & -- & -- \\
\hline & 750 & -- & -- & -- & -- & -- & -- & -- & -- & -- & -- & -- & -- & -- & -- & -- & -- & -- & -- & $\begin{array}{c}143 \\
(290)\end{array}$ & -- & -- & -- & -- & -- \\
\hline & 1000 & $\begin{array}{r}268 \\
(515) \\
\end{array}$ & $\begin{array}{c}260 \\
(500) \\
\end{array}$ & $\begin{array}{r}244 \\
(472) \\
\end{array}$ & $\begin{array}{r}258 \\
(496) \\
\end{array}$ & $\begin{array}{l}12.2 \\
(22) \\
\end{array}$ & $\begin{array}{c}247 \\
(476) \\
\end{array}$ & $\begin{array}{l}254 \\
490 \\
\end{array}$ & $\begin{array}{l}238 \\
459 \\
\end{array}$ & $\begin{array}{l}269 \\
517 \\
\end{array}$ & $\begin{array}{l}254 \\
489 \\
\end{array}$ & $\begin{array}{c}16.1 \\
29 \\
\end{array}$ & $\begin{array}{l}256 \\
493 \\
\end{array}$ & -- & -- & -- & -- & -- & -- & $\begin{array}{c}153 \\
(308) \\
\end{array}$ & $\begin{array}{c}151 \\
(303) \\
\end{array}$ & $\begin{array}{c}152 \\
(305) \\
\end{array}$ & $\begin{array}{c}152 \\
(305) \\
\end{array}$ & $\begin{array}{l}1.7 \\
(3)\end{array}$ & $\begin{array}{c}149 \\
(301) \\
\end{array}$ \\
\hline \multirow{4}{*}{ Solstice PF } & 200 & -- & -- & -- & -- & -- & -- & -- & -- & -- & -- & -- & -- & -- & -- & -- & -- & -- & -- & $\mathrm{TL}$ & -- & -- & -- & -- & -- \\
\hline & 500 & -- & -- & -- & -- & -- & -- & -- & -- & -- & -- & -- & -- & -- & -- & -- & -- & -- & -- & $\begin{array}{c}192 \\
(378)\end{array}$ & -- & -- & -- & -- & -- \\
\hline & 750 & -- & -- & -- & -- & -- & -- & -- & -- & -- & -- & -- & -- & -- & -- & -- & -- & -- & -- & $\begin{array}{c}187 \\
(369)\end{array}$ & -- & -- & -- & -- & -- \\
\hline & 1000 & $\begin{array}{r}245 \\
(473) \\
\end{array}$ & $\begin{array}{c}246 \\
(474) \\
\end{array}$ & $\begin{array}{c}230 \\
(446) \\
\end{array}$ & $\begin{array}{r}240 \\
(464) \\
\end{array}$ & $\begin{array}{c}8.9 \\
(16) \\
\end{array}$ & -- & $\begin{array}{c}247 \\
(476) \\
\end{array}$ & $\begin{array}{c}244 \\
(471) \\
\end{array}$ & $\begin{array}{c}251 \\
(484) \\
\end{array}$ & $\begin{array}{r}247 \\
(477) \\
\end{array}$ & $\begin{array}{l}3.9 \\
(7) \\
\end{array}$ & -- & -- & -- & -- & -- & -- & -- & $\begin{array}{c}192 \\
(359) \\
\end{array}$ & $\begin{array}{c}180 \\
(356) \\
\end{array}$ & $\begin{array}{c}185 \\
(365) \\
\end{array}$ & $\begin{array}{c}182 \\
(360) \\
\end{array}$ & $\begin{array}{l}2.8 \\
(5) \\
\end{array}$ & -- \\
\hline \multirow{4}{*}{ L-14780 } & 200 & -- & -- & -- & -- & -- & -- & -- & -- & -- & -- & -- & -- & -- & -- & -- & -- & -- & -- & $\mathrm{TL}$ & -- & -- & -- & -- & -- \\
\hline & 500 & -- & -- & -- & -- & -- & -- & -- & -- & -- & -- & -- & -- & -- & -- & -- & -- & -- & -- & $\begin{array}{c}167 \\
(333)\end{array}$ & -- & -- & -- & -- & -- \\
\hline & 750 & -- & -- & -- & -- & -- & -- & -- & -- & -- & -- & -- & -- & -- & -- & -- & -- & -- & -- & $\begin{array}{c}168 \\
(334)\end{array}$ & -- & -- & -- & -- & -- \\
\hline & 1000 & TL & TL & TL & TL & -- & -- & $\mathrm{TL}$ & TL & TL & TL & -- & -- & $\begin{array}{r}234 \\
(454) \\
\end{array}$ & -- & -- & $\begin{array}{c}234 \\
(454)^{*}\end{array}$ & -- & -- & $\begin{array}{c}167 \\
(332) \\
\end{array}$ & $\begin{array}{c}152 \\
(305) \\
\end{array}$ & $\begin{array}{c}166 \\
(330) \\
\end{array}$ & $\begin{array}{c}161 \\
(322) \\
\end{array}$ & $\begin{array}{r}8.3 \\
(15) \\
\end{array}$ & -- \\
\hline \multirow{4}{*}{ AK225G } & 200 & -- & -- & -- & -- & -- & -- & -- & -- & -- & -- & -- & -- & -- & -- & -- & -- & -- & -- & $\mathrm{TL}$ & $\mathrm{TL}$ & $\mathrm{TL}$ & $\mathrm{TL}$ & -- & -- \\
\hline & 500 & -- & -- & -- & -- & -- & -- & -- & -- & -- & -- & -- & -- & -- & -- & -- & -- & -- & -- & $\begin{array}{c}226 \\
(438)\end{array}$ & $\begin{array}{c}230 \\
(446)\end{array}$ & $\begin{array}{c}235 \\
(454)\end{array}$ & $\begin{array}{c}230 \\
(446)\end{array}$ & $\begin{array}{l}4.4 \\
(8)\end{array}$ & -- \\
\hline & 750 & -- & -- & -- & -- & -- & -- & -- & -- & -- & -- & -- & -- & -- & -- & -- & -- & -- & -- & $\begin{array}{c}236 \\
(456)\end{array}$ & -- & -- & $\begin{array}{c}236 \\
(456)\end{array}$ & -- & -- \\
\hline & 1000 & TL & TL & TL & TL & -- & -- & $\begin{array}{r}273 \\
(523) \\
\end{array}$ & $\begin{array}{c}278 \\
(532) \\
\end{array}$ & $\begin{array}{c}276 \\
(528) \\
\end{array}$ & $\begin{array}{r}276 \\
(528) \\
\end{array}$ & $\begin{array}{l}2.8 \\
(5) \\
\end{array}$ & -- & -- & -- & -- & -- & -- & -- & $\begin{array}{r}230 \\
(446) \\
\end{array}$ & -- & -- & $\begin{array}{c}230 \\
(446)^{*} \\
\end{array}$ & -- & \\
\hline \multirow{4}{*}{ HFE-7100 } & 200 & -- & -- & -- & -- & -- & -- & -- & -- & -- & -- & -- & -- & -- & -- & -- & -- & -- & -- & $\mathrm{TL}$ & $\mathrm{TL}$ & TL & $\mathrm{TL}$ & -- & -- \\
\hline & 500 & -- & -- & -- & -- & -- & -- & -- & -- & -- & -- & -- & -- & -- & -- & -- & -- & -- & -- & $\begin{array}{c}337 \\
(639)\end{array}$ & $\begin{array}{c}341 \\
(646)\end{array}$ & $\begin{array}{c}336 \\
(636)\end{array}$ & $\begin{array}{c}338 \\
(640)\end{array}$ & $\begin{array}{l}2.8 \\
(5)\end{array}$ & -- \\
\hline & 750 & -- & -- & -- & -- & -- & -- & -- & -- & -- & -- & -- & -- & -- & -- & -- & -- & -- & -- & $\begin{array}{c}327 \\
(620)\end{array}$ & -- & -- & $\begin{array}{c}327 \\
(620)\end{array}$ & -- & -- \\
\hline & 1000 & TL & TL & TL & TL & -- & -- & $\begin{array}{c}381 \\
(718)\end{array}$ & $\begin{array}{c}392 \\
(738)\end{array}$ & $\begin{array}{c}393 \\
(740) \\
\end{array}$ & $\begin{array}{c}389 \\
(732)\end{array}$ & $\begin{array}{r}6.7 \\
(12)\end{array}$ & -- & -- & -- & -- & -- & -- & -- & $\begin{array}{c}332 \\
(629)\end{array}$ & -- & -- & $\begin{array}{c}332 \\
(629)^{*}\end{array}$ & -- & \\
\hline
\end{tabular}

